\title{
EXPOSITA NOTE
}

Bert M. Balk · Rolf Färe · Shawna

Grosskopf · Dimitris Margaritis

\section{Exact relations between Luenberger productivity indicators and Malmquist productivity indexes}

Received: 1 March 2006 / Revised: 8 February 2007 /

Published online: 13 March 2007

(C) Springer-Verlag 2007

Abstract In this note we derive an exact relation between Luenberger productivity indicators and Malmquist productivity indexes.

Keywords Luenberger productivity indicator - Malmquist productivity index · Logarithmic mean

\section{JEL Classification Numbers C43 - D24}

The Malmquist productivity index based on Shephard's distance function has become a standard tool in economics. Introduced by Caves et al. (1982) it has been shown by the same authors to be the theoretical foundation of the Törnqvist index. The Malmquist index has also been directly estimated using activity analysis or data envelopment analysis (see Färe et al. 1998 for a survey).

The Luenberger productivity indicator, introduced by Chambers (2002), is also based on distance functions, albeit directional distance functions rather than Shephard type distance functions, where the former are additive in structure and the latter multiplicative. In this paper, we show how the Luenberger productivity indicator can be transformed into the Malmquist productivity index. Our results follow from choosing a specific directional vector for the directional distance function.

The authors are grateful for referee comments which substantially improved the paper.

B. Balk

Statistics Netherlands and RSM Erasmus University, Rotterdam, Netherlands

R. Färe $(\varangle) \cdot$ S. Grosskopf

Department of Economics, Oregon State University,

303 Ballard, Corvallis, OR 97331, USA

E-mail: rolf.fare@orst.edu

D. Margaritis

AUT, Faculty of Busniess, Auckland, New Zealand 
In a recent paper Boussemart et al. (2003) showed that the Malmquist index is a linear approximation of the Luenberger indicator, but they did not discuss their exact relationship.

We begin with some notation: denote input quantities by $x \in \mathfrak{R}_{+}^{N}$, output quantities by $y \in \Re_{+}^{M}$, and the technology by

$$
T^{\tau}=\{(x, y): x \text { can produce } y \text { in period } \tau\} .
$$

The Malmquist productivity index, introduced by Caves et al. (1982), is defined as ratio of distance function values. In particular the base (0) period output oriented Malmquist productivity index is defined as

$$
M_{o}^{0}=\frac{D_{o}^{0}\left(x^{1}, y^{1}\right)}{D_{o}^{0}\left(x^{0}, y^{0}\right)},
$$

where $\left(x^{\tau}, y^{\tau}\right)(\tau=0,1)$ is an observed $\tau$-period input-output vector and where

$$
D_{o}^{\tau}(x, y)=\inf \left\{\theta:(x, y / \theta) \in T^{\tau}\right\}(\tau=0,1) .
$$

The corresponding Luenberger productivity indicator, introduced by Chambers (2002, first version in 1996) is defined as (see also Chambers et al. 1996)

$$
\mathfrak{f}^{0}(g)=\vec{D}_{T}^{0}\left(x^{0}, y^{0} ; g\right)-\vec{D}_{T}^{0}\left(x^{1}, y^{1} ; g\right),
$$

where $g=\left(g_{x}, g_{y}\right)$ is a directional vector and where the directional technology distance function is defined as

$$
\vec{D}_{T}^{\tau}(x, y ; g)=\sup \left\{\beta:\left(x-\beta g_{x}, y+\beta g_{y}\right) \in T^{\tau}\right\}(\tau=0,1) .
$$

The two distance functions are related by

$$
\vec{D}_{T}^{\tau}\left(x, y ; 0_{N}, y\right)=1 / D_{o}^{\tau}(x, y)-1(\tau=0,1) .
$$

That is we set $g_{x}=0_{N}$ and $g_{y}=y$, which implies that we are projecting $(x, y)$ on the frontier of $T^{\tau}$ in the direction of $y$.

Following the suggestion of an anonymous referee, to relate the Malmquist index (2) to the Luenberger indicator (4), we use (6) to obtain

$$
\mathfrak{£}^{0}\left(0_{N}, y^{1}\right)=\vec{D}_{T}^{0}\left(x^{0}, y^{0} ; 0_{N}, y^{1}\right)+1-1 / D_{o}^{0}\left(x^{0}, y^{0}\right) M_{o}^{0} .
$$

This expression shows the relation between the Malmquist index $M_{o}^{0}$ and the Luenberger indicator $\mathfrak{£}^{0}\left(0_{N}, y^{1}\right)$; note, however that this relationship also depends on the distance functions $\vec{D}_{T}^{0}\left(x^{0}, y^{0} ; 0_{N}, y^{1}\right)$ and $D_{o}^{0}\left(x^{0}, y^{0}\right)$. We can remove this dependency by assuming that

$$
\vec{D}_{T}^{0}\left(x^{0}, y^{0} ; 0_{N}, y^{0}\right)=0 .
$$

This assumption is similar to that made by Caves et al. (1982) and it says that $\left(x^{0}, y^{0}\right)$ is on the frontier of technology $T^{0}$. The following lemma shows that, given some assumptions, (8) implies that $\vec{D}_{T}^{0}\left(x^{0}, y^{0} ; 0_{N}, y^{1}\right)$ also is equal to zero. Hence, since (8) is equivalent to $D_{o}^{0}\left(x^{0}, y^{0}\right)=1$, we obtain a direct relation between the Malmquist index and the Luenberger indicator. 
Lemma Assume that the period 0 technology exhibits strong disposability of outputs (i.e., $\left(y^{\prime \prime}, x\right) \in T^{0}$ and $y^{\prime} \leq y^{\prime \prime}$ implies that $\left.\left(y^{\prime}, x\right) \in T^{0}\right)$ and that $y_{m}^{1}>$ $0, m=1, \ldots$, M. If $\vec{D}_{T}^{0}\left(x^{0}, y^{0} ; 0_{N}, y^{0}\right)=0$ then $\vec{D}_{T}^{0}\left(x^{0}, y^{0} ; 0_{N}, y^{1}\right)=0$.

Proof Suppose that $\vec{D}_{T}^{0}\left(x^{0}, y^{0} ; 0_{N}, y^{1}\right)=\beta>0$. This means that $\left(x^{0}, y^{0}+\right.$ $\left.\beta y^{1}\right) \in T^{0}$. Let $\gamma=\min \left\{\beta y_{m}^{1} / y_{m}^{0} ; y_{m}^{0}>0, m=1, \ldots, M\right\}$. Then $\gamma>0$. Since $y^{0}+\gamma y^{0} \leq y^{0}+\beta y^{1}$, strong disposability of the technology implies that $\left(x^{0}, y^{0}+\gamma y^{0}\right) \in T^{0}$. But this means that $\vec{D}_{T}^{0}\left(x^{0}, y^{0} ; 0_{N}, y^{0}\right) \geq \gamma>0$, which contradicts our supposition.

Thus by (8) and the assumptions of the lemma we have established the following relation between the Malmquist index and the Luenberger indicator defined on the $T^{0}$ technology,

$$
\mathfrak{£}^{0}\left(0_{N}, y^{1}\right)=1-1 / M_{o}^{0} .
$$

One may also define a Malmquist index and a Luenberger indicator relative to the later period technology $T^{1}$. From this it follows that, under similar assumptions,

$$
£^{1}\left(0_{N}, y^{0}\right)=1-1 / M_{o}^{1} .
$$

Note the symmetry in the relationship between the directional and Shephard distance functions in (6) and the expressions in (9) and (10).

In empirical applications, the geometric mean version of the Malmquist index is frequently employed, i.e.,

$$
M_{o}=\left(M_{o}^{0} M_{o}^{1}\right)^{1 / 2},
$$

where $M_{o}^{1}$ is the comparison period (1) Malmquist index, defined relative to $T^{1}$. The corresponding Luenberger indicator is an arithmetic mean

$$
£=\left(\mathfrak{£}^{0}+\mathfrak{£}^{1}\right) / 2 .
$$

In order to relate the two average expressions to each other we make use of the logarithmic mean which is defined for two positive real numbers $a$ and $b$ as

$$
L(a, b)=(a-b) / \ln (a / b) \text { and } L(a, a)=a .
$$

Balk (2003) attributes the introduction of this mean in economics to L. Törnqvist; see Törnqvist et al. (1985).

Applying the logarithmic mean to expression (9) yields

$$
\ln 1-\ln \left(1 / M_{o}^{0}\right)=£^{0} / L\left(1,1 / M_{o}^{0}\right)
$$

or

$$
M_{o}^{0}=e^{\mathfrak{£}^{0} / L\left(1,1 / M_{o}^{0}\right)} .
$$

Similarly for the period 1 expression (10),

$$
M_{o}^{1}=e^{\mathfrak{£}^{1} / L\left(1,1 / M_{o}^{1}\right)} .
$$

Hence,

$$
\begin{aligned}
& M_{o}=\left(M_{o}^{0} M_{o}^{1}\right)^{1 / 2} \\
& =e^{1 / 2\left(£^{0} / L\left(1,1 / M_{o}^{0}\right)+£^{1} / L\left(1,1 / M_{o}^{1}\right)\right)},
\end{aligned}
$$

which gives us a relation between the two average expressions (11) and (12). 


\section{References}

Balk, B.M.: The residual: on monitoring and benchmarking firms, industries and economies with respect to productivity. J Product Anal 20, 5-47 (2003)

Boussemart, J.-P., Briec W., Kerstens K., Poutineau, J.-C.: Luenberger and Malmquist productivity indices: theoretical comparisons and empirical illustration. Bull Econ Res 55, 391-405 (2003)

Caves, D., Christensen, L., Diewert, W.E.: The economic theory of index numbers and the measurement of input, output, and productivity. Econometrica 50, 1393-1414 (1982)

Chambers, R.G.: Exact nonradial input, output, and productivity measurement. Econ Theory 20, 751-765 (2002)

Chambers, R., Färe, R., Grosskopf, S.: Productivity growth in APEC Countries. Pac Econ Rev 1, 181-190 (1996)

Färe, R., Grosskopf, S., Roos, P.: Malmquist productivity indexes: a survey of theory and practice. In: Färe, R., Grosskopf, S., Russell, R.R. (eds.) Index numbers: essays in honor of Sten Malmquist. Boston: Kluwer (1998)

Törnqvist, L., Vartia, P., Vartia, Y.O.: How should relative changes be measured? Am Stat 39, $43-46(1985)$ 